\title{
DISTRIBUTIONAL AND MORPHOLOGICAL CHANGES IN EXCESS CEMENTITE DURING DEFORMATION OF HYPEREUTECTOID STEELS
}

\author{
S. V. Burov*, Yu. V. Khudorozhkova \\ Institute of Engineering Science, Ural Branch of the Russian Academy of Sciences, 620049, 34 Komsomolskaya st., \\ Ekaterinburg, Russian Federation \\ *Corresponding author. E-mail: burchitai@mail.ru; address for correspondence: ul. Komsomolskaya 34, 620049, \\ Ekaterinburg, Russian Federation. Tel.:+7 343 3753583; fax: +7 3433745330
}

Obtaining of layered excess cementite distribution in hypereutectoid steel by deformation in the intercritical temperature range is considered. The initial state prior to deformation is cast steel and heat treated cast steel. It has been revealed that in the cast state excess cementite can be represented in the form of plates in a volume of austenite grains, in the form of network along austenite grain boundaries, in the form of liquation-induced aggregates (tangles) in the interaxial intervals of austenite dendrites. Typically a cast structure contains all of these morphologies. Sometimes excess cementite can be represented as primary cementite in nonequilibrium ledeburite. It has been found that a reliable method to obtain the layered structure without the presence of coarse particles of cementite is deformation in the intercritical temperature range of hypereutectoid carbon steel with an initial Widmanstätten morphology of excess carbide phase.

Keywords: excess cementite, Widmanstätten cementite, wootz steel, hypereutectoid steel, cementite network.

DOI: $10.17804 / 2410-9908.2015 .6 .80-89$

\section{References}

1. Wadsworth J., Sherby O.D. On the bulat-damascus steels revisited. Progress in Materials Science, 1980, vol. 25, no. 1, pp. 35-68. DOI: 10.1016/0079-6425(80)90014-6.

2. Feuerbach A. Crucible Damascus steel: A fascination for almost 2,000 years. Jom, 2006, vol. 58, no. 5, pp. 48-50. DOI: 10.1007/s11837-006-0023-y.

3. Sherby O.D., Wadsworth J. Ancient blacksmiths, the Iron Age, Damascus steels, and modem metallurgy. Journal of Materials Processing Technology, 2001, vol. 117, no. 3, pp. 347-353. DOI: 10.1016/s0924-0136(01)00794-4.

4. Verhoeven J.D., Pendray A.H., Dauksch W.E. The key role of impurities in ancient damascus steel blades. Jom-Journal of the Minerals Metals \& Materials Society, 1998, vol. 50, no. 9, pp. 58-64. DOI: 10.1007/s11837-998-0419-y.

5. Wadsworth J., Sherby O.D. Response to Verhoeven comments on Damascus steel. Materials Characterization, 2001, vol. 47, no. 2, pp. 163-165. DOI: 10.1016/s1044-5803(01)00184-X.

6. Taleff E.M., Bramfitt B.L., Syn C.K., Lesuer D.R., Wadsworth J., Sherby O.D. Processing, structure, and properties of a rolled, ultrahigh-carbon steel plate exhibiting a damask pattern. Materials Characterization, 2001, vol. 46, no. 1, pp. 11-18. DOI: 10.1016/s1044-5803(00)00087-5. 7. Burov S.V., Khudorozhkova Yu.V., Ryzhkov M.A. Peculiarities of austenite transformation under continuous cooling of hypereutectoid steel. Obrabotka Metallov. Metal Working and Material Science, 2013, no. 4 (61), pp. 65-70. (In Russian).

8. Barnett M.R., Sullivan A., Balasubramaniam R. Electron backscattering diffraction analysis of an ancient wootz steel blade from central India. Materials Characterization, 2009, vol. 60, no. 4, pp. 252-260. DOI: 10.1016/j.matchar.2008.10.004.

9. Sherby O.D. Ultrahigh carbon steels, Damascus steels and ancient blacksmiths. ISIJ International, 1999, vol. 39, no. 7, pp. 637-648. DOI: 10.2355/isijinternational.39.637.

10. Verhoeven J.D. Genuine Damascus steel: a type of banded microstructure in hypereutectoid steels. Steel Research, 2002, vol. 73, no. 8, pp. 356-365. 
11. Bataev V.A., Bataev A.A., Kotorov S.A., Tushinskii L.I. Special features of the fracture of ordered segregated excess cementite in eutectoid steels. Metal Science and Heat Treatment, 1999, vol. 41, no. 3-4, pp. 101-104. DOI: 10.1007/bf02467693.

12. Bataev I.A., Bataev, A.A., Burov, V.G., Lizunkova, Ya.S., Zakharevich, E.E. Structure of widmanstatten crystals of ferrite and cementite. Steel in translation, 2008, vol. 38, no. 8, pp. 684-687.

Burov S.V. et al. / Distributional and morphological changes in excess cementite during deformation of hypereutectoid steels 
Подана в журнал: 30.10 .2015

УДК 669.017

DOI: $10.17804 / 2410-9908.2015 .6 .80-89$

\title{
ИЗМЕНЕНИЕ МОРФОЛОГИИ И РАСПРЕДЕЛЕНИЯ ИЗБЫТОЧНОГО ЦЕМЕНТИТА В ПРОЦЕССЕ ДЕФОРМИРОВАНИЯ ЗАЭВТЕКТОИДНЫХ СТАЛЕЙ
}

\author{
С. В. Буров*, Ю. В. Худорожкова \\ Федеральное государственное бюджетное учреждение науки Институт машиноведения \\ Уральского отделения Российской академии наук, ул. Комсомольская, 34, Екатеринбург, Российская Федерация \\ *Ответственный автор. Электронная почта: burchitai@mail.ru; адрес для переписки: ул. Комсомольская, 34, \\ 620049, Екатеринбург, Российская Федерация. Телефон: +7 (343) 375-35-83; факс: +7 (343) 374-53-30
}

В работе рассмотрено получение слоистого распределения избыточного цементита в заэвтектоидной стали за счет деформации в межкритическом интервале температуры. В качестве исходного состояния, предшествовавшего деформированному, рассматривалась сталь как с литой, так и сформированной в процессе термообработки структурой. Выявлено, что в литом состоянии избыточный цементит может быть представлен в виде пластин в объеме аустенитного зерна, сетки по границам аустенитного зерна и скоплений (клубков) ликвационной природы в межосевых промежутках дендритов аустенита. Обычно в структуре представлен цементит нескольких морфологий. Отдельно можно выделить первичный цементит в составе неравновесного ледебурита. Установлено, что надежным методом получения слоистой структуры без наличия грубодисперсных частиц цементита является деформирование в межкритическом интервале температур заэвтектоидной углеродистой стали с избыточной карбидной фазой исходной видманштеттовой морфологии.

Ключевые слова: избыточный цементит, Видманштеттов цүементит, булат, цементитная сетка, заэвтектоидная сталь.

\section{1. Введение}

В современных представлениях булат - это первая литая углеродистая сталь, имеющая в кованом состоянии композиционную структуру [1-3]. По данным работы [4], структура булата представляет собой композицию, в которой глобулярные мелкодисперсные частицы вторичного цементита залегают в сорбитной матрице слоями. Они же подчеркивают, что главную роль в образовании слоистости булатов играют примеси активных карбидообразователей, таким образом неявно указывая, что механизмы формирования слоистого распределения карбидов схожи с механизмами формирования карбидной строчечности современных легированных сталей.

Их научные оппоненты Шерби и Водсворт [5] в многочисленных публикациях заявляют, что современные исследования исторических образцов булатов показывают отсутствие сколь-либо значительных примесей карбидообразующих элементов, а формирование структуры со слоистым залеганием мелкодисперсных глобулярных частиц избыточного цементита происходит исключительно благодаря деформированию в межкритическом интервале (между $\mathrm{Ac}_{1}$ и $\mathrm{Ac}_{\mathrm{M}}$ ) [6]. Неравномерность залегания примесей практически всегда имеет дендритную природу, далекую от характера распределения цементитных частиц в булатах. По мнению Шерби и Водсворта, слоистое распределение формируется при дроблении и сфероидизации частиц цементитной сетки, полученной отжигом $[1,6]$. Высокотемпературный длительный отжиг и последующая деформация в межкритическом интервале составляют основу механизма Шерби - Водсворта. Мнение этих ученых с материаловедческой позиции более обоснованны и аргументированны, однако их собственные результаты [6] далеки от истинно слоистого распределения карбидных частиц в деформированной стали.

Настоящие исследования базировались на предположении, что для формирования слоистой композиционной структуры ковка должна проводиться при температурах ниже суBurov S.V. et al. / Distributional and morphological changes in excess cementite during deformation of hyper-

eutectoid steels 
ществования гомогенного аустенита. Была поставлена задача выявить исходную морфологию избыточного цементита, пригодную для получения естественного композиционного материала на основе заэвтектоидной стали.

Реконструкция исторической булатной технологии не входила в задачи настоящего исследования.

Цели работы - исследовать морфологию и характер распределения избыточного вторичного цементита в литых и кованых углеродистых заэвтектоидных сталях и определить микроструктуру, пригодную для формирования естественного композиционного материала со слоистым распределением мелкодисперсного глобулярного цементита.

\section{2. Материалы и методика эксперимента}

В качестве материалов исследований использовали заэвтектоидные углеродистые стали. Исследовали сталь, полученную тигельной плавкой в пламенной печи, сталь У16 индукционной выплавки, а также сталь У16ш, полученную методом электрошлакового переплава (ЭШП) стали У16.

Объекты исследований - слитки в кристаллизованном по различным режимам состоянии, слитки, подвергнутые полному отжигу, а также полосы, полученные протяжкой слитков в интервале температур ковки $850-700{ }^{\circ} \mathrm{C}$, гарантированно ниже точки $\mathrm{A}_{\text {См}}$, составлявшей $960{ }^{\circ} \mathrm{C}[7]$.

Исследования проводились на металлографическом инвертированном микроскопе АльтамиМЕТ1М, был использован метод светлопольного металлографического анализа на микрошлифах, полученных по традиционной технологии, включающей в себя такие операции как вырезка образцов, шлифование на шлифовальных шкурках с последовательным уменьшением зернистости, шлифование на алмазных пастах и полирование на суспензии оксида хрома. Травление шлифов производили ниталем (5\%-й раствор азотной кислоты в спирте).

\section{3. Результаты исследований и их обсуждение}

\section{1 Структура литой заэвтектоидной стали}

Исследовали структуру литой стали, закристаллизованной с различными скоростями охлаждения. Структура стали У16 индукционной выплавки, разлитой в холодную керамическую изложницу (рис. 1), показывает, что в морфологии избыточного цементита литой стали влияние оказывают процессы внутризеренной ликвации. Избыточный цементит представлен в виде сетки по границам бывшего аустенитного зерна (столбчатые зерна с диаметром около 300-500 мкм и длиной до 4 мм), массивных цементитных клубков или узелков ликвационной природы, декорирующих межосевые промежутки бывших аустенитных дендритов, а также пластин, выглядящих как иглы, вторичного цементита видманштеттова типа. Видно (рис. 1 б), что цементитные клубки являются скоплением повышенного числа игл видмаштеттова цементита, следовательно их происхождение определяется выделением из твердого раствора с повышенной концентрацией углерода.

Структура стали после ЭШП, при котором кристаллизация ведется в медном водоохлаждаемом кристаллизаторе, т. е. с высокой скоростью, схожа, но характеризуется более высокой дисперсностью (рис. 2).

Структура заэвтектоидной стали опытной тигельной плавки, подвергнутой выдержке в интервале температур между солидусом и ликвидусом с последующим быстрым охлаждением тигля на спокойном воздухе, характеризуется наличием неравновесного ледебурита по границам, а также игл видманштеттова цементита внутри бывшего аустенитного зерна (рис. 3).

Burov S.V. et al. / Distributional and morphological changes in excess cementite during deformation of hypereutectoid steels 
opten-aceess journal

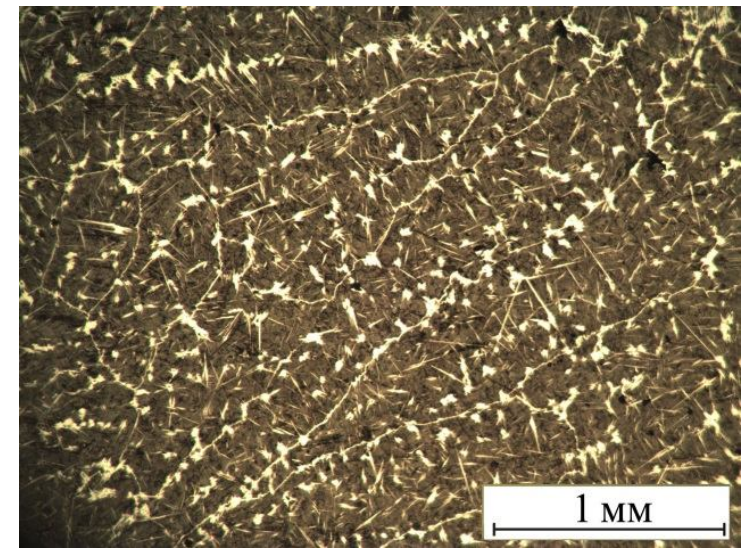

$a$

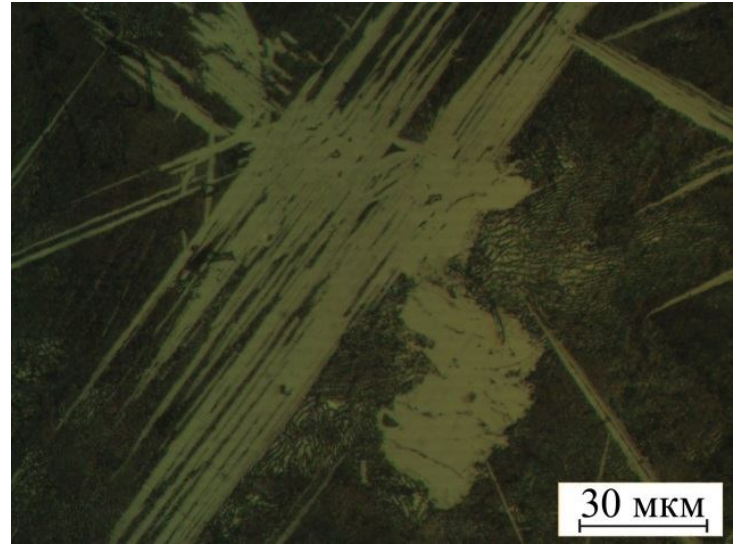

$\sigma$

Рис. 1. Структура стали У16, подвергнутой разливке в холодную керамическую изложницу, при разных увеличениях $(a, \sigma)$. Слиток массой 20 кг

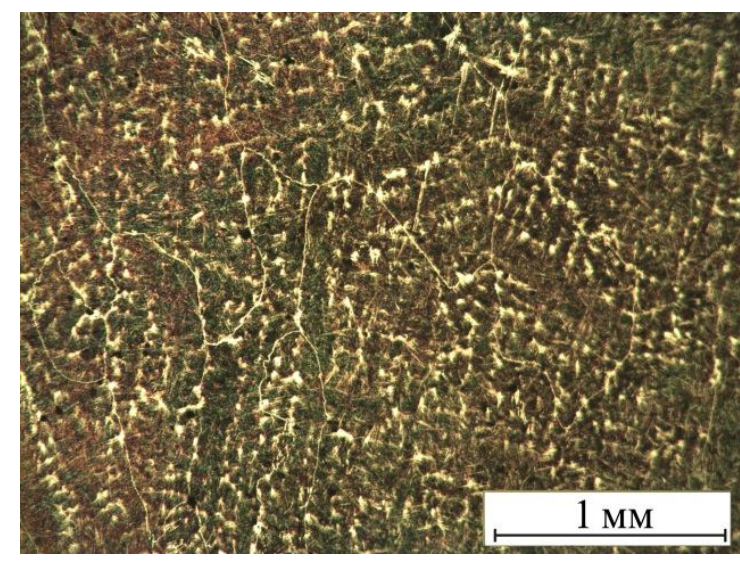

$a$

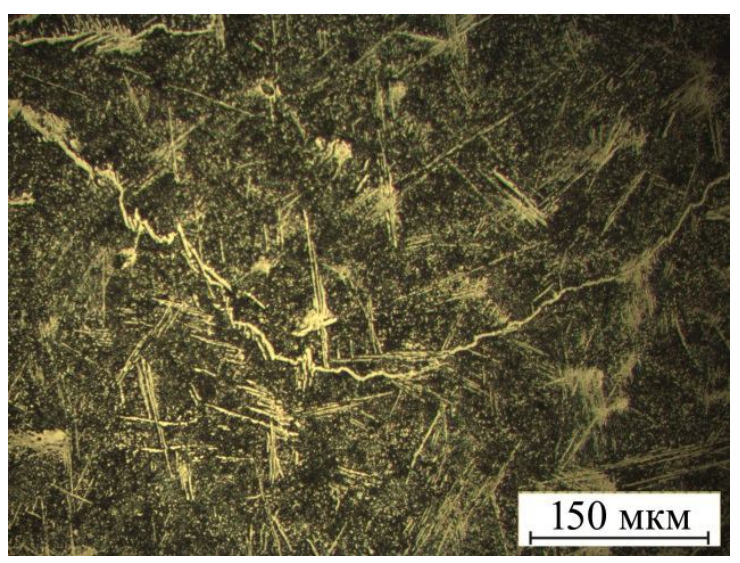

6

Рис. 2. Структура литой стали У16ш при разных увеличениях $(a, \sigma)$

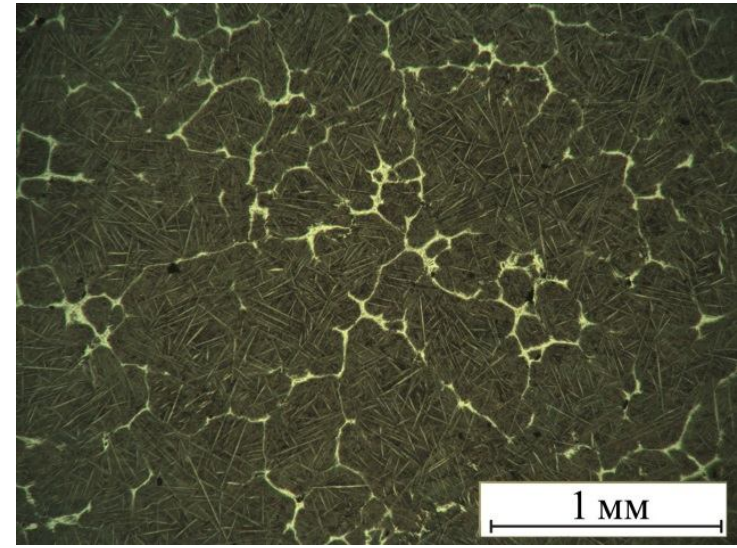

$a$

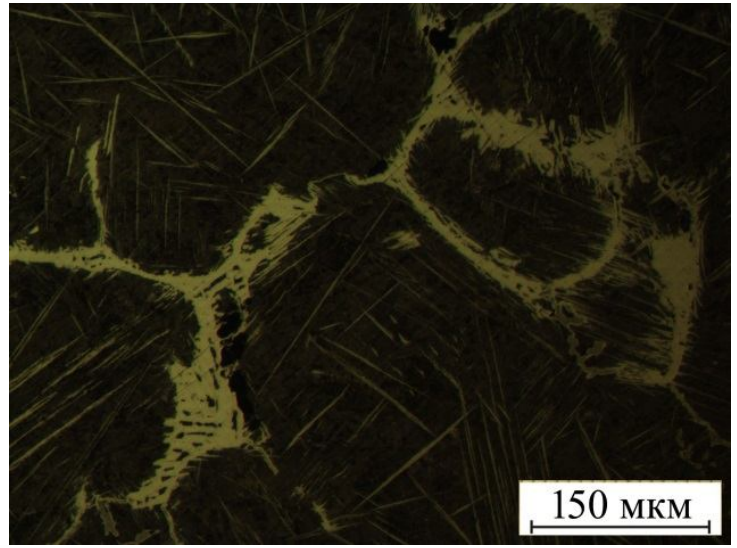

$\sigma$

Рис. 3. Структура стали У16, подвергнутой выдержке в интервале между ликвидусом и солидусом и последующему быстрому охлаждению, при разных увеличениях $(a, \sigma)$

Полный отжиг стали У16 с температурой гомогенизации аустенита $1100{ }^{\circ} \mathrm{C}$ (время выдержки 120 минут) приводит к классическому выделению избыточного (вторичного) це-

Burov S.V. et al. / Distributional and morphological changes in excess cementite during deformation of hypereutectoid steels 
opetr-access jurrnal

ментита в виде массивной цементитной сетки по границам бывшего аустенитного зерна (рис. 4).

Кристаллизация при тигельной плавке в условиях, предельно снижающих дендритную ликвацию, приводит к формированию тонкой цементитной сетки, незначительному количеству клубков, а основной объем избыточного цементита выделяется в виде пластин видманшеттова типа (рис. 5). Применение разработанных режимов охлаждения не позволило получить однородную пластинчатую морфологию при кристаллизации легированной стали (проводились опытные плавки на основе ШХ15 с добавками графита).

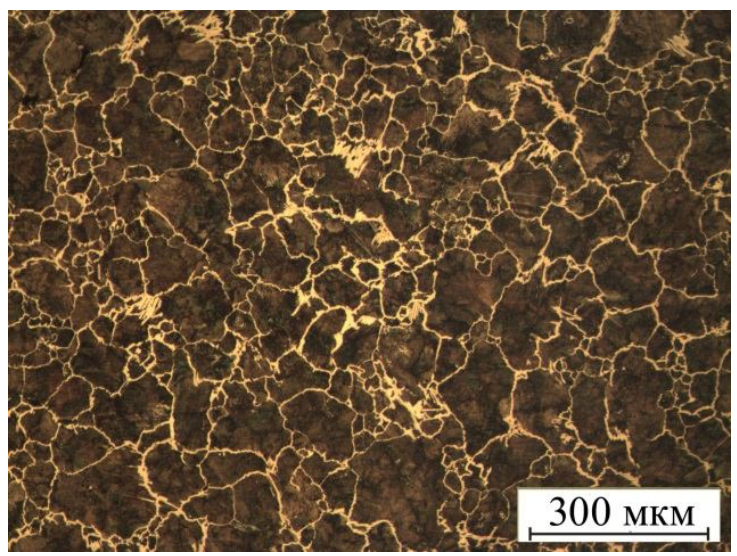

Рис. 4. Структура стали У16, подвергнутой отжигу с температурой аустенитизации $1100{ }^{\circ} \mathrm{C}$

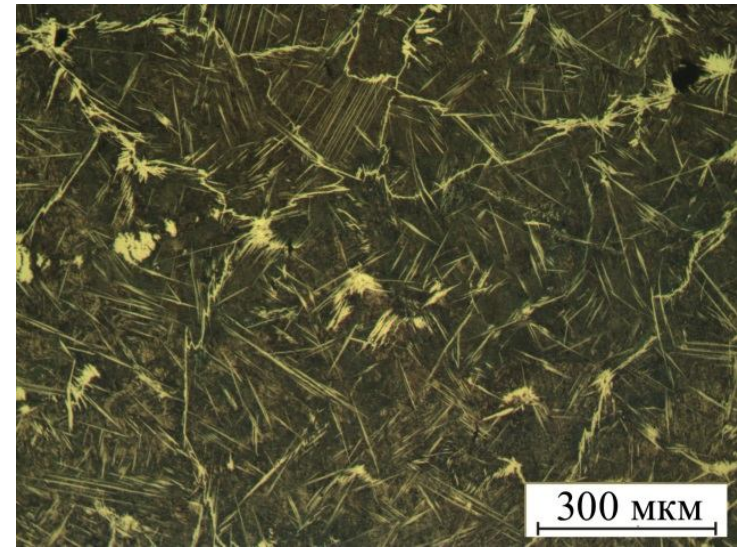

$a$

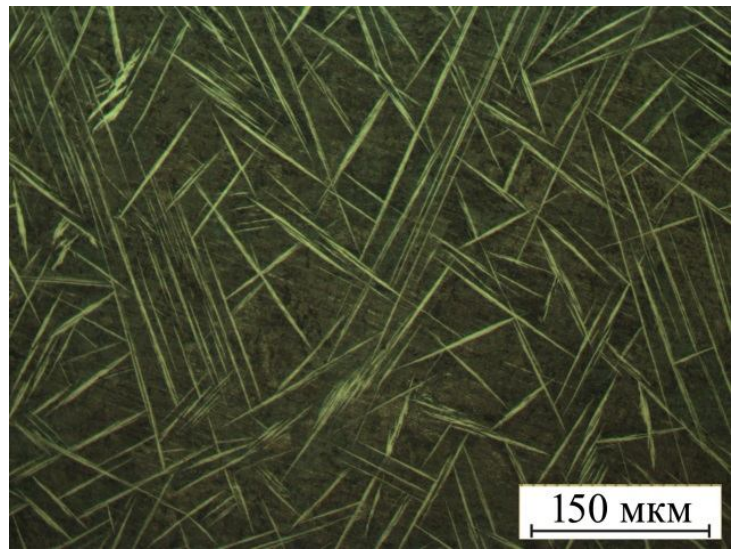

$\sigma$

Рис. 5. Пластинчатая морфология избыточного цементита видманштеттова типа в заэвтектоидной углеродистой стали при разных увеличениях $(a, \sigma)$

При анализе полученных структур выявлено, что избыточный цементит в литой заэвтектоидной стали может быть представлен в виде пластин в объеме аустенитного зерна, в виде сетки по границам аустенитного зерна, в виде скоплений (клубков) ликвационной природы в межосевых промежутках дендритов аустенита. Отдельно можно выделить первичный цементит в составе неравновесного ледебурита.

С позиции наследования распределения избыточного цементита в процессе дробления и сфероидизации при ковке, «претендентами» на формирование слоистого распределения глобулярного мелкодисперсного цементита в кованой заэвтектоидной стали являются структуры с исходно двухмерными построениями: с видманштеттовыми пластинами и сеткой.

Burov S.V. et al. / Distributional and morphological changes in excess cementite during deformation of hypereutectoid steels 
open-access journal

\section{2 Структура поковок}

Образцы исследованных сталей подвергли ковке с вытяжкой в полосу. В процессе ковки вытяжка составила около $1000 \%$.

Распределение избыточных карбидов в разлитой в изложницу и подвергнутой ковке

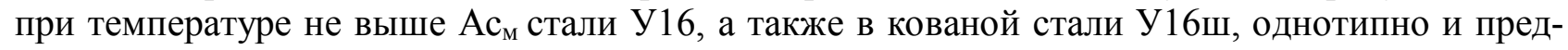
ставлено на рис. 6 и 7. В структуре произошло диспергирование и измельчение карбидной фазы, однако не приходится говорить о строго слоистом распределении, скорее имеется карбидная строчечность и карбидная неоднородность по типу легированных инструментальных сталей. Размер избыточных карбидных частиц неравномерен, имеются включения частиц размером около 10...20 мкм. Эти крупные выделения могут расцениваться с позиции обеспечения свойств как неметаллические включения. Подобная структура заэвтектоидной стали, содержащая избыточные цементитные частицы разных размеров, описана в работе [8].

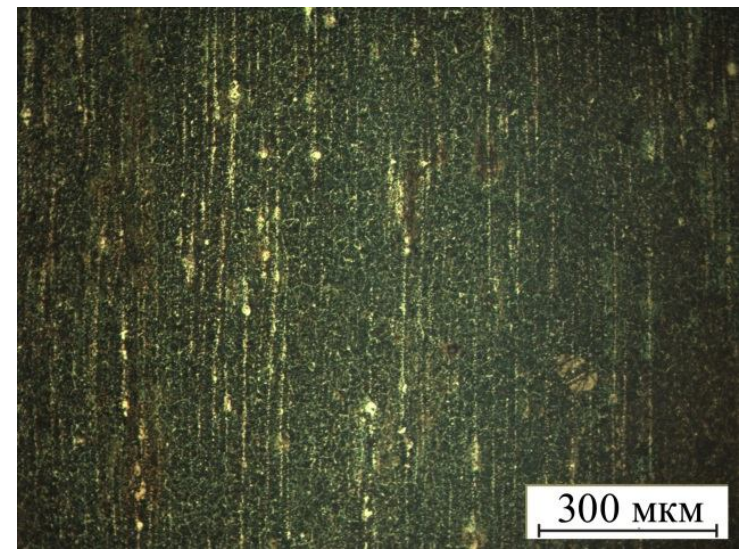

$a$

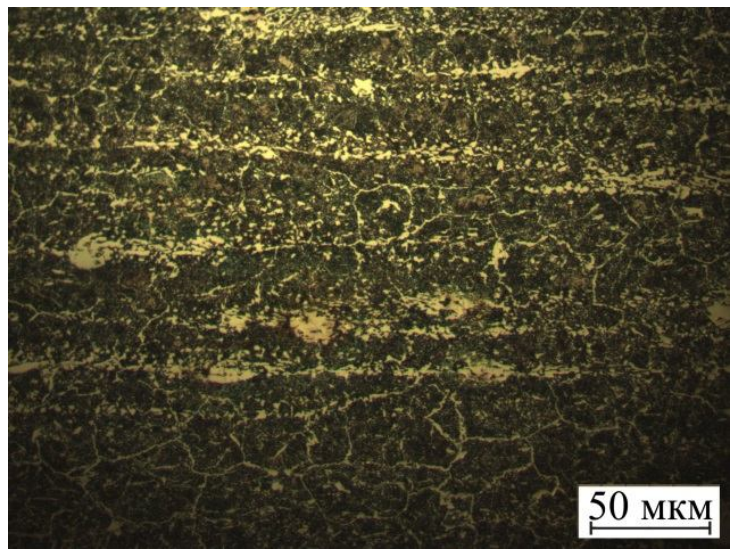

$\sigma$

Рис. 6. Структура стали У16ш, подвергнутой ковке при температуре ниже $\mathrm{Ac}_{\mathrm{m}}$. Микрошлиф продольного сечения при разных увеличениях $(a, \sigma)$

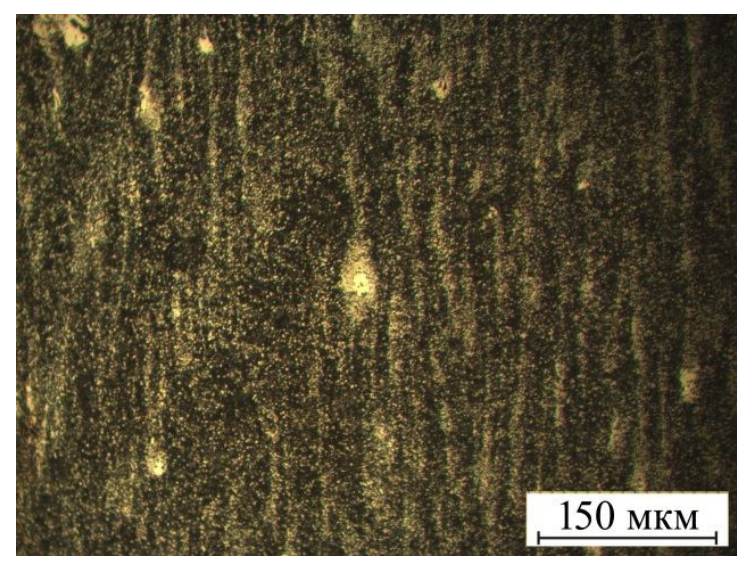

$a$

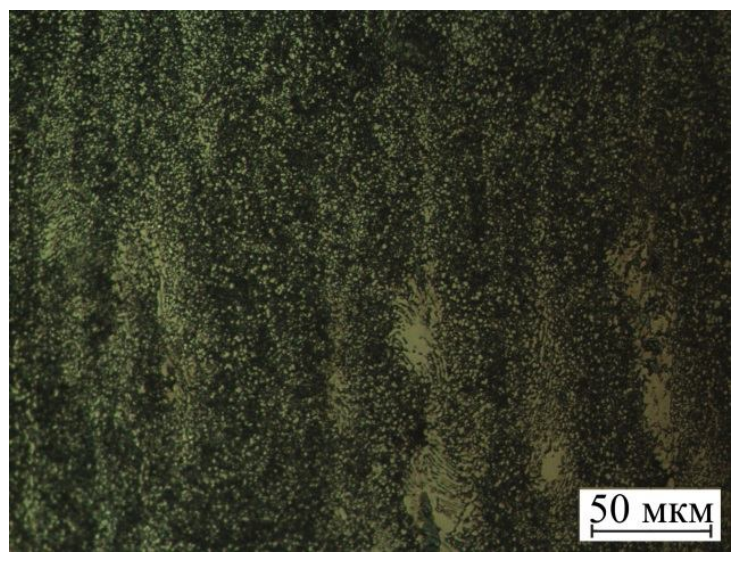

6

Рис. 7. Структура стали У16ш, подвергнутой ковке при температуре ниже $\mathrm{Ac}_{\mathrm{M}}$. Микрошлиф поперечного сечения при разных увеличениях $(a, \sigma)$

Распределение карбидных частиц в кованой стали при наличии в исходной структуре неравновесного ледебурита также не может быть охарактеризовано как чисто слоистое. Сильно выражена неоднородность размера карбидных частиц (рис. 8). В структуре имеются карбидные включения до 50 мкм (рис. 8 б). 
open-access journal

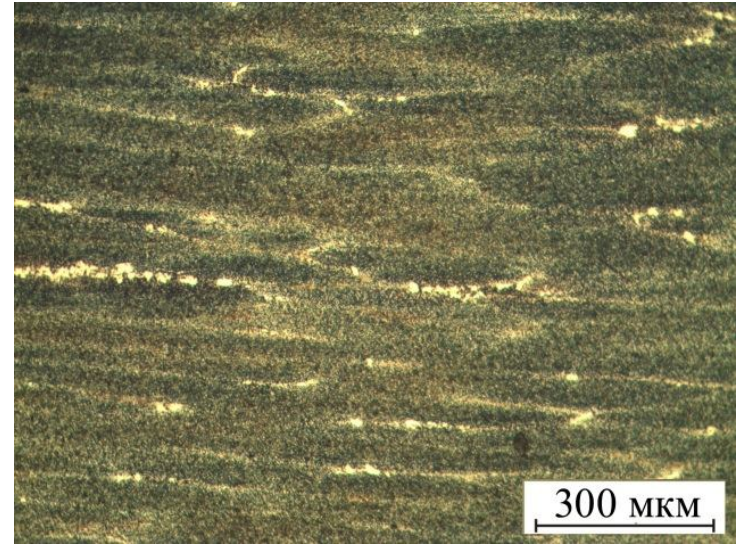

$a$

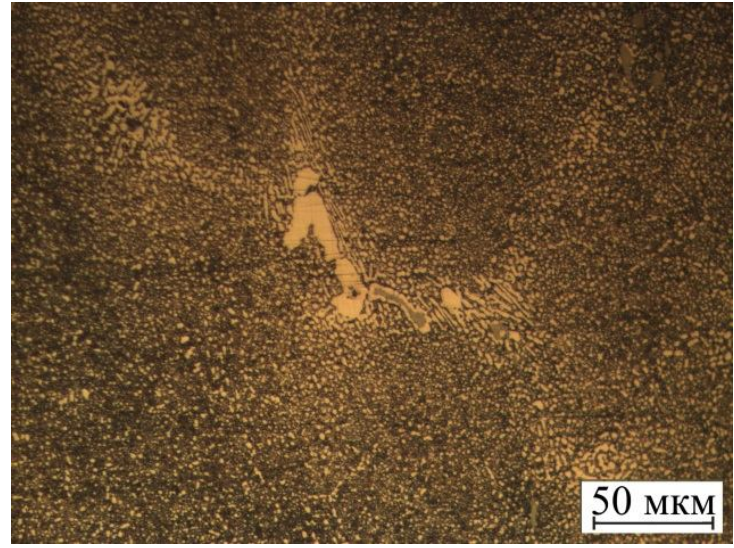

$\sigma$

Рис. 8. Структура заэвтектоидной стали с исходным наличием неравновесного ледебурита после ковки при температуре ниже $\mathrm{Ac}_{\mathrm{M}}$. Микрошлиф поперечного сечения при разных увеличениях $(a, \sigma)$

Структура кованой в межкритическом интервале стали У16 с исходной морфологией вторичного цементита в виде грубой сетки показывает (рис. 9) как отсутствие четко выраженной слоистости с параллельными слоями, так и наличие карбидной неоднородности. Однако структура, сформированая по механизму Водсворта-Шерби, менее контрастна, чем в работах авторов, применявших для деформирования прокатку и не получивших в структуре карбидной неоднородности по размерам частиц [9].

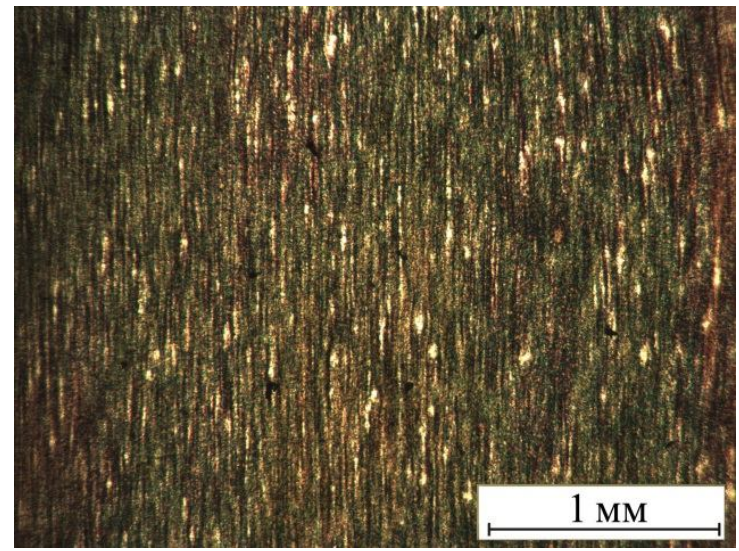

$a$

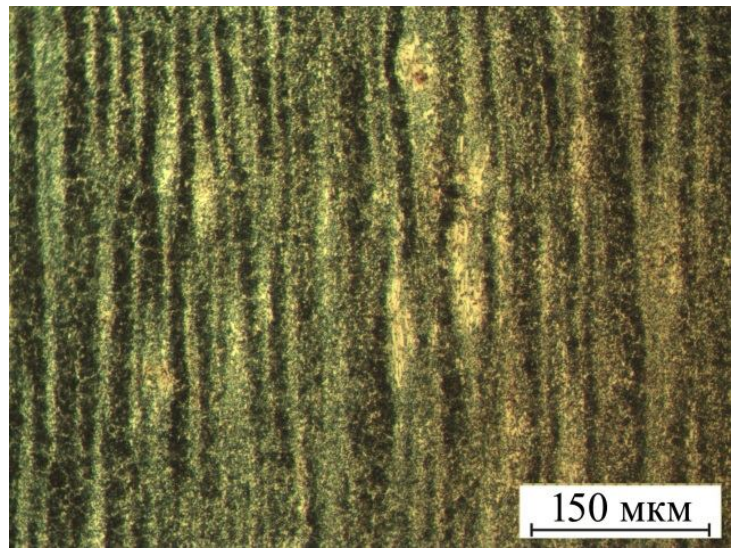

б

Рис. 9. Структура кованой в межкритическом интервале стали У16 с исходной сеточной морфологией избыточного цементита при разных увеличениях $(a, \sigma)$

Ковка в межкритическом интервале стали с исходной видманштеттовой морфологией избыточного цементита и отсутствием сильно выраженных ликвационных карбидных неоднородностей приводит к формированию слоистой структуры с мелкодисперсными (менее 1-3 мкм) частицами избыточного цементита (рис. 10) и получению макроструктуры слоистого композиционного материала (рис. 11). Эта структура соответствует искомой, т. е. не содержит крупных частиц цементита, которые имеют четко выраженное слоистое залегание, а также соотвествует микроструктуре исторических образцов булатной стали [4, 10]. Поведение пластин видманштеттова цементита, их дробление на начальных стадиях деформирования описано в работах $[11,12]$.

Burov S.V. et al. / Distributional and morphological changes in excess cementite during deformation of hypereutectoid steels 
open-aCCeSS journal

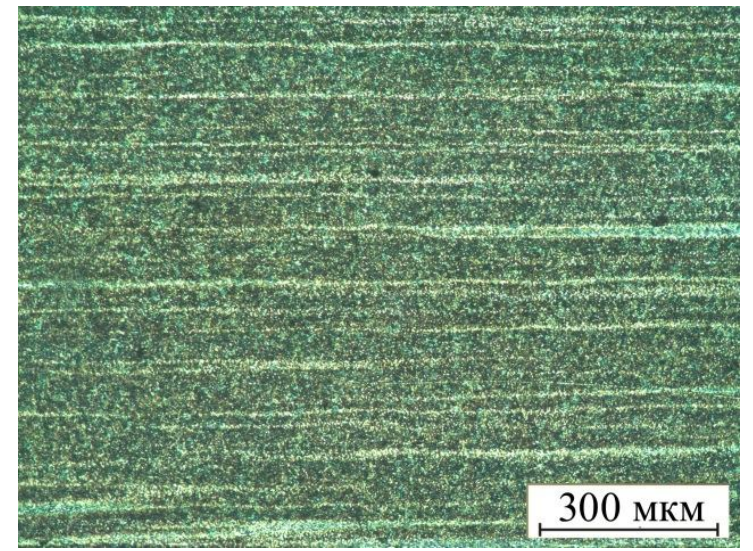

$a$

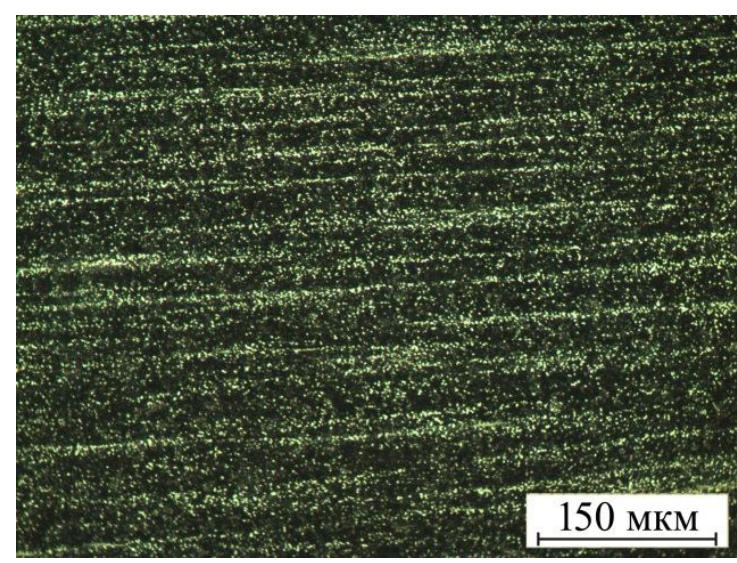

B

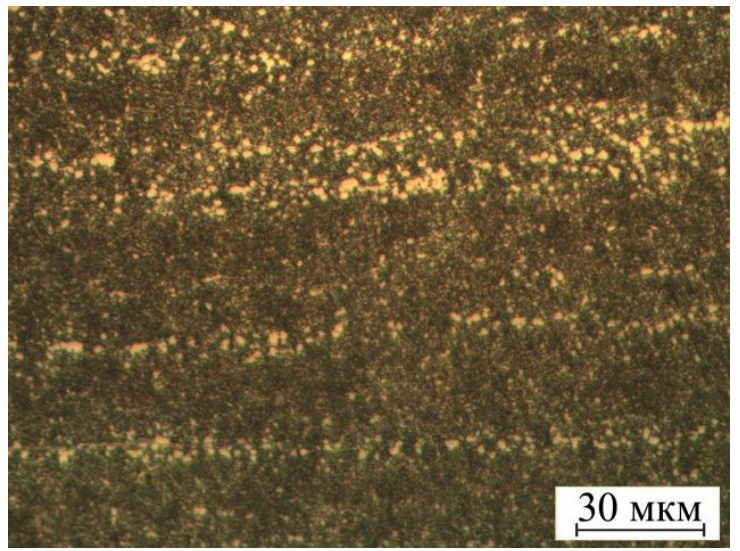

$\sigma$

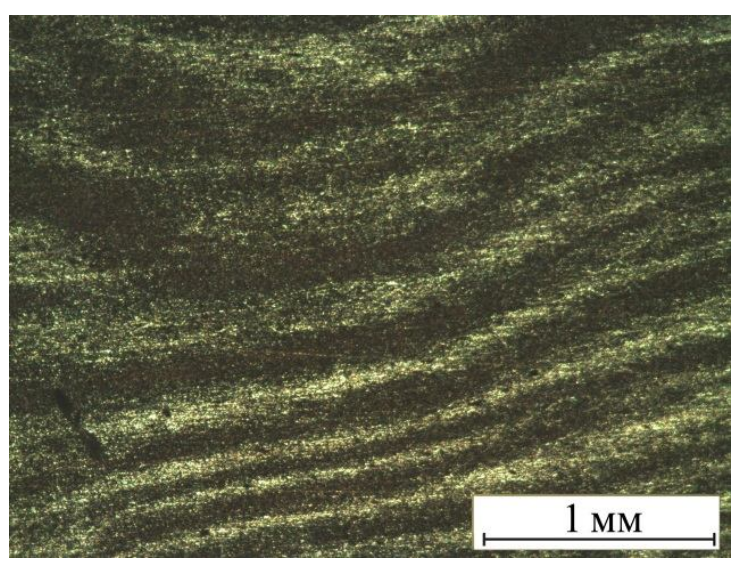

2

Рис. 10. Структура кованой в межкритическом интервале заэвтектоидной стали с исходной игольчатой видманштеттовой морфологией избыточного цементита: $a, \sigma$ - продольное сечение; в - поперечное сечение; 2 - структура поверхности полосы

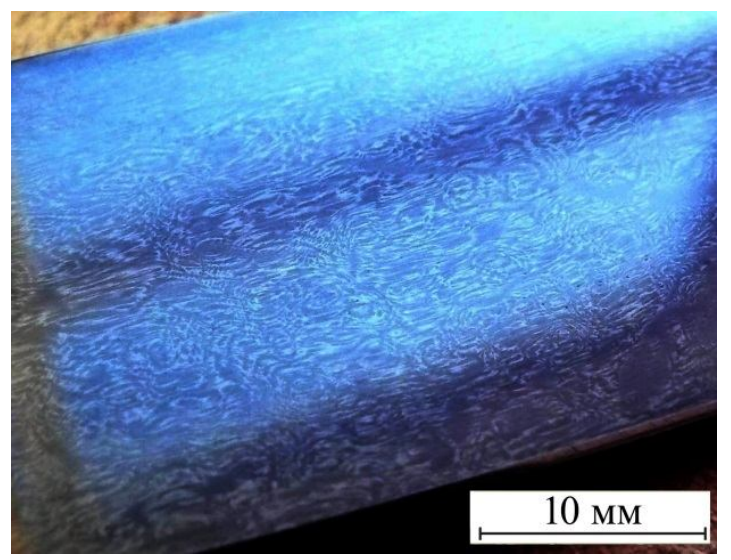

Рис. 11. Макроструктура полученного композиционного материала

\section{4. Выводы}

1. В работе показано, что избыточный цементит в литой заэвтектоидной стали может быть представлен в виде пластин в объеме бывшего аустенитного зерна, в виде сетки по границам зерна, в виде скоплений (клубков) ликвационной природы в межосевых промежутках дендритов аустенита. Отдельно можно выделить первичный цементит в составе неравновесного ледебурита.

Burov S.V. et al. / Distributional and morphological changes in excess cementite during deformation of hypereutectoid steels 
2. В результате проведенных исследований установлено, что надежным методом получения слоистой структуры без наличия грубодисперсных частиц цементита является деформирование заэвтектоидной углеродистой стали с исходной видманштеттовой морфологией избыточной карбидной фазы в межкритическом интервале температур. При выполнении этих условий естественный слоистый композиционный материал на основе заэвтектоидной стали может быть получен без применения специальных видов обработки, направленных на измельчение и сфероидизацию избыточной карбидной фазы.

\section{Литература}

1. Wadsworth J., Sherby O. D. On the bulat-damascus steels revisited // Progress in Materials Science. - 1980. - Vol. 25, № 1. - P. 35-68. DOI: 10.1016/0079-6425(80)90014-6.

2. Feuerbach A. Crucible Damascus steel: A fascination for almost 2,000 years // Jom. -2006. - Vol. 58, № 5. - P. 48-50. DOI: 10.1007/s11837-006-0023-y.

3. Sherby O. D., Wadsworth J. Ancient blacksmiths, the Iron Age, Damascus steels, and modem metallurgy // Journal of Materials Processing Technology. - 2001. - Vol. 117, № 3. P. 347-353. DOI: 10.1016/s0924-0136(01)00794-4.

4. Verhoeven J. D., Pendray A. H., Dauksch W. E. The key role of impurities in ancient damascus steel blades // Jom-Journal of the Minerals Metals \& Materials Society. - 1998. Vol. 50, № 9. - C. 58-64. DOI: 10.1007/s11837-998-0419-y.

5. Wadsworth J., Sherby O. D. Response to Verhoeven comments on Damascus steel // Materials Characterization. - 2001. - Vol. 47, № 2. - P. 163-165. DOI: 10.1016/s1044-5803(01)00184-X.

6. Taleff E. M., Bramfitt B. L., Syn C. K., Lesuer D. R., Wadsworth J., Sherby O. D. Processing, structure, and properties of a rolled, ultrahigh-carbon steel plate exhibiting a damask pattern // Materials Characterization. - 2001. - Vol. 46, № 1. - P. 11-18. DOI: 10.1016/s1044-5803(00)00087-5.

7. Буров С. В., Худорожкова Ю. В., Рыжков М. А. Особенности распада аустенита при непрерывном охлаждении перегретой заэвтектоидной стали // Обработка металлов. (Технология, Оборудование, Инструменты). - 2013. № 4 (61). - С. 65-70.

8. Barnett M. R., Sullivan A., Balasubramaniam R. Electron backscattering diffraction analysis of an ancient wootz steel blade from central India // Materials Characterization. - 2009. - Vol. 60, № 4. - P. 252-260. DOI: 10.1016/j.matchar.2008.10.004.

9. Sherby O. D. Ultrahigh carbon steels, Damascus steels and ancient blacksmiths // ISIJ International. - 1999. - Vol. 39, № 7. - P. 637-648. DOI: 10.2355/isijinternational.39.637.

10. Verhoeven J. D. Genuine Damascus steel: a type of banded microstructure in hypereutectoid steels // Steel Research. - 2002. - Vol. 73, № 8. - P. 356-365.

11. Bataev V. A., Bataev A. A., Kotorov S. A., Tushinskii L. I. Special features of the fracture of ordered segregated excess cementite in eutectoid steels // Metal Science and Heat Treatment. 1999. - Vol. 41, № 3-4. - P. 101-104. DOI: 10.1007/bf02467693.

12. Bataev I. A., Bataev, A. A., Burov, V. G., Lizunkova, Ya. S., Zakharevich, E. E. Structure of widmanstatten crystals of ferrite and cementite // Steel in translation. - 2008. - Vol. 38, № 8. P. 684-687. 